\title{
Hermenêutica e interpretação constitucional sistemática axioteleológica*
}

\author{
Edihermes Marques Coelho" \\ Recebido: 21 de junho de 2016 • Aprovado: 18 de julho de 2017 \\ DOI: 10.22395/ojum.v16n32a7
}

\section{RESUMO}

Os processos hermenêuticos são processos comunicacionais em que a linguagem é a ferramenta de condução de mensagens, cujos sentidos são redefinidos constantemente. No âmbito do direito, os enunciados linguísticos são organizados especialmente em normas jurídicas a serem interpretadas. A atividade hermenêutica jurídica organiza-se em torno de possibilidades argumentativas que se destinam a definir a mais adequada interpretação para a solução dos problemas concretos da vida. Entretanto, essa definição não fica à livre disposição do intérprete, pois há referências normativas prévias, cujo conteúdo axiológico e teleológico há de ser respeitado de forma que se preserve a sistematicidade constitucional.

Palavras-chave. Hermenêutica constitucional; princípios e regras; sistema jurídico.

\footnotetext{
Trabalho elaborado no âmbito do projeto de pesquisa em fluxo contínuo sobre a eficácia dos Direitos Fundamentais no sistema jurídico, sob a coordenação do autor, vinculado ao Programa de Mestrado em Direito Público da Universidade Federal de Uberlândia (UFU), Uberlândia, Minas Gerais, Brasil.

** Mestre e doutor em Direito pela Universidade Federal de Santa Catarina (UFSC). Professor do curso de Direito da Faculdade de Direito e do mestrado em Direito Público da UFU. E-mail: edihermescoelho@gmail.com.
} 


\title{
Hermeneutics and constitutional systematic axiotheological interpretation
}

\begin{abstract}
Hermeneutical processes are communication processes in which language is the toll used to pass messages on; messages which senses are constantly redefined. In a legal framework, linguistic utterances are specially organized on legal norms to be interpreted. The legal hermeneutic activity is organized around argumentative possibilities intended to define the most appropriate interpretation for the solution of concrete daily-life problems. However, this definition is not freely available to the interpreter, as there are previous normative references, whose axiological and theleological content must be respected so as to preserve constitutional systematicity.
\end{abstract}

Keywords: constitutional Hermeneutics; legall system; principles and rules.

\section{Hermenéutica e interpretación constitucional sistemática axioteleológica}

\section{RESUMEN}

Los procesos hermenéuticos son procesos comunicacionales en los que el lenguaje es la herramienta de conducción de mensajes, cuyos sentidos se redefinen constantemente. En el marco del derecho, los enunciados lingüísticos se organizan especialmente en normas jurídicas a interpretarse. La actividad hermenéutica jurídica se organiza alrededor de posibilidades argumentativas que se destinan a definir la más adecuada interpretación para la solución de problemas concretos de la vida. Sin embargo, esta definición no queda a disposición del intérprete, pues hay referencias normativas previas, cuyo contenido axiológico y teleológico se deben respetar de forma que se preserve la sistematicidad constitucional.

Palabras clave: hermenéutica constitucional; principios y reglas; sistema jurídico. 


\section{INTRODUCÃO}

Num mundo de relações humanas balizadas por normas jurídicas que transitam entre o efetivo e o não efetivo, há um Direito em crise. O cenário atual caracteriza-se por crises diversas, embora interligadas: crise econômica, crise de identidade cultural, crise política, crise ambiental. O Direito, enquanto matriz funcional de normatização das relações humanas, acompanha seu objeto de regulação, e ele próprio precisa se reconstruir nesse contexto. Tal reconstrução passa pela reconstrução de aspectos normativos e dogmáticos que dependem de operações interpretativas e hermenêuticas para que suas funções jurídico-regulatórias sejam efetivadas.

No âmbito da comunicação humana, a etimologia da palavra hermenêutica reporta ao verbo grego hermeneuein e ao substantivo hermeneia (Alberti, 1996). O deus Hermes tinha como função traduzir as mensagens dos deuses aos humanos, fazendo com que a linguagem divina fosse compreensível pela inteligência humana. Os gregos creditavam a Hermes a descoberta da linguagem e da escrita, com a função de mensageiro dos deuses.

A hermenêutica, assim, tem como origem a necessidade de interpretação de mensagens, para torná-las compreensíveis. Ora, o Direito configura-se como um conjunto de comunicações normativas, cuja definição de sentido é complexa e, por vezes, é contraditória culturalmente. Desse modo, a interpretação dos textos jurídicos tem sido uma das questões mais relevantes da teoria jurídica contemporânea. As discussões vão desde qual é o real objeto da interpretação jurídica, passam pela seleção do(s) método(s) adequado(s) para a atividade interpretativa e chegam às possibilidades e aos limites da interpretação jurídica.

Os processos interpretativos das normas jurídicas são condicionados por parâmetros hermenêuticos para a compreensão. A hermenêutica jurídica pode ser definida, então, como a parte da ciência jurídica que tem por objeto o estudo e a sistematização dos processos que devem ser utilizados para a realização da interpretação. A partir dela, delineiam-se os mecanismos interpretativos. Com isso, a interpretação, por sua vez, consistiria na utilização dos critérios hermenêuticos para a definição de sentido(s) para os textos jurídicos legislados ou não (França, 1994, pp. 21-22; Peixinho, 2003, pp. 14-15).

Tais preocupações têm sua razão de ser. Como o Direito é construído a partir do uso da linguagem ordinária em enunciados comunicativos de caráter prescritivo (contidos em normas, que em sua maioria são legisladas), o sentido que a linguagem possui, ao ser utilizada em tais enunciados, passa a ser uma questão decisiva para se dimensionar a atuação dos profissionais do Direito e, por consequência, para se dimensionar a própria efetividade das normas jurídicas. Por um lado, trata-se de firmar o conteúdo com o qual o Direito intervém na realidade regulada; por outro, trata-se de indicar as diretrizes a serem seguidas pelos profissionais jurídicos nessa tarefa. 
O Direito não está limitado à lei e consiste num conjunto complexo de conteúdos, dos quais a lei é a face mais aparente e importante, mas não a única. Tal importância está sediada, sobretudo, na circunstância de que é através da lei que o Estado propaga comandos diretos para condutas pessoais e comportamentos institucionais, além de fixar parâmetros para isso. Assim, em virtude da importância operacional que a legislação possui, a atividade interpretativa é pensada a partir dos parâmetros para a interpretação legal. Não é admissível, entretanto, que a interpretação fique limitada a isso.

Enfim, no que respeita às possibilidades e aos limites interpretativos, há dois âmbitos: um é aquele que se refere à sistematicidade do Direito e sua vinculação normativa à Constituição; outro é aquele que se refere aos limites do papel político cultural do hermeneuta, especialmente na atividade judicial. Desse modo, não se deve desprezar que a interpretação dentro do jurídico está relacionada a diversas condicionantes não jurídicas, de caráter ideológico e cultural — mas este trabalho aqui apresentado se refere ao problema da sistematicidade do Direito e sua vinculação hermenêutico-normativa à Constituição.

Numa abordagem dedutiva, como fruto de pesquisa bibliográfica e exploratória, o estudo aqui desenvolvido sobre os parâmetros hermenêuticos de interpretação jurídica sistemática passa: (a) pela compreensão do papel da linguagem na comunicação humana; (b) pelo estudo dos principais métodos interpretativos de que dispõem os operadores do Direito; (c) pela prevalência dos valores constitucionais superiores no plano interpretativo, com destaque para a essencialidade funcional da interpretação sistemática axioteleológica.

\section{OS SIGNOS E A TRANSMISSÃO DE CONTEÚDOS}

Em normas, textos jurídicos, decisões judiciais, como em quase qualquer esfera da vida, os seres humanos se comunicam através da utilização da linguagem escrita. Esta consiste num meio de transmissão de conteúdos, um meio de comunicação - o meio de comunicação por excelência, já que se caracteriza como atemporal.

A linguagem pode ser definida, pois, como o conjunto de instrumentos de comunicação, que possibilitam a transmissão articulada de mensagens entre os seres humanos. Nesse sentido, ensina Vanoye (1986) que a linguagem é
[...] um sistema de signos social- izado. "Socializado" remete clara- mente à função de comunica- ção da linguagem. A expressão "sistema de signos" é empregada para definir a linguagem como um conjunto cujos elementos se de- terminaram em suas inter-relações, ou seja, um conjunto no qual nada significa em si, mas tudo significa em função dos outros elementos. Em outras palavras, o sentido de um termo, bem como o de um enunciado, é função do contexto em que ele ocorre. (p. 29)

A comunicação humana ocorre, portanto, através de mecanismos simbólicos aos 
quais atribuímos significados específicos, os signos. Estes se caracterizam como unidades de linguagem, meios de comunicação que traduzem sentidos. Cada signo linguístico carrega um potencial significado, o que é decisivo para a comunicação quando são agrupados. Assim, a palavra cadeira, enquanto signo linguístico, indica, a quem a lê ou a ouve, um sentido, designa para nossas mentes um objeto. Vanoye (1986) explica que o

[...] signo é a menor unidade dot-
ada de sentido num código dado.
Decompõe-se num elemento ma-
terial, perceptível, o significante,
e num elemento conceptual, não
perceptível, o significado (por
exemplo, a palavra "mesa" pode
ser ouvida ou vista, conforme seja
pronunciada ou escrita: o som
"mesa" e a forma gráfica "mesa"
são significantes que remetem ao
mesmo significado, o conceito
de mesa, "objeto constituído por
uma superfície plana sustentada
por um ou mais pés"). O referente
é o objeto real ao qual remete o
signo numa instância de enuncia-
ção. (p. 59 )

Agrupados, os signos nos possibilitam apresentar concepções sobre as coisas corpóreas e incorpóreas, com maior ou menor complexidade. Os significados potenciais dos signos se multiplicam de acordo com as combinações que fazemos entre eles. Desse modo, a uma palavra podem ser agregadas outras, dimensionando e especificando diversos sentidos.

Além disso, a utilização da linguagem não é linear nos agrupamentos humanos.
Numa mesma cidade, convivem pessoas de diferentes camadas culturais, com diferentes formas de ver e viver a vida, e de conviver com as demais pessoas. Isso faz com que as pessoas tenham diferentes matrizes culturais e que gerem variações no padrão de uso da linguagem, especialmente da linguagem ordinária, cotidiana. Embora a linguagem culta seja relevante na comunicação qualificada (a jurídica incluída), em larga escala, a linguagem ordinária determina as possibilidades comunicacionais.
[...] alguns dos seus termos po- dem ser entendidos de várias maneiras. Mas o significado ap- ropriado é definido pelo contexto verbal e factual, do qual cada pa- lavra é uma parte, se bem que, se forem tomadas separadamente, elas equivalem a uma pura abstra- ção e não, em absoluto, a uma lin- guagem. (Aranguren, 1975, p. 79)

Além disso, não se deve menosprezar a circunstância de o uso da linguagem poder ocorrer de forma pretensamente denotativa (o sentido real) ou de forma pretensamente conotativa (o sentido figurado ou decorrente de interpretação). Em virtude de tais aspectos, nenhum tipo de comunicação é exata, perfeita. Pelo mesmo motivo, pode-se dizer que a verdade é sempre, em algum grau e de algum modo, relativa, dependente do ato de interpretar (Gadamer, 2003) No Direito, o modo como são articulados os signos é próprio, específico da comunicação jurídica. É inegável, aliás, que o modo como articulamos os signos nas frases já implica uma maior ou menor capacidade individual de trans- 
missão de conteúdos (comunicação) e de expressão de pensamentos, correlacionada às próprias intenções subjacentes de quem formula o discurso (no caso, normativo). Não obstante, independentemente dessas variações no padrão de uso da linguagem e das intenções subjacentes, existe uma forma culta de utilização dos signos e de construção das expressões linguísticas (entende-se por forma culta de utilização da linguagem o emprego dos padrões gramaticais e ortográficos consagrados como adequados à correta expressão linguística).

O ideal, em termos de comunicação humana - e em termos de comunicação prescritiva jurídica —, é procurar otimizar a comunicação utilizando-se da linguagem com o máximo potencial comunicativo permitido pelas circunstâncias de seu uso.

Assim também o é no plano jurídico, embora a especificidade da comunicação jurídica, baseada em enunciados normativos, exija parâmetros específicos de uso da linguagem e parâmetros específicos na formulação dos enunciados linguísticos normativos.

\section{A LINGUAGEM NO DIREITO}

A legislação, a jurisprudência e os princípios jurídicos são formas (institucionais ou não) de comunicação humana, e as formas principais de comunicação dentro do Direito. Não se está desprezando aqui o papel dos textos doutrinários como fontes do Direito. Apenas se ressalta o fato evidente de que, sendo o Direito um fenômeno basicamente normativo, a teoria já opera sobre a legislação, a jurisprudência e os princípios jurídicos gerais, que seriam a matéria-prima da dogmática jurídica. Os artigos de lei, os julgamentos, os mandamentos principiológicos possuem enunciados de comunicação dirigidos a outros seres humanos. Para tanto, utilizam-se da linguagem e dos recursos atinentes à linguagem e à comunicação humana, condicionadas por parâmetros ideológicos e interesses sociais.

Como afirma Larenz (1989),

$$
\begin{aligned}
& \text { [...] que o significado preciso de } \\
& \text { um texto legal seja constante- } \\
& \text { mente problemático depende, em } \\
& \text { primeira linha, do fato de a lin- } \\
& \text { guagem corrente, de que a lei se } \\
& \text { serve em grande medida, não uti- } \\
& \text { lizar, ao contrário de uma lógica } \\
& \text { axiomatizada e da linguagem das } \\
& \text { ciências, conceitos cujo âmbito } \\
& \text { esteja rigorosamente fixado, mas } \\
& \text { termos mais ou menos flexíveis, } \\
& \text { cujo significado possível oscila } \\
& \text { dentro de uma larga faixa e que } \\
& \text { pode ser diferente segundo as } \\
& \text { circunstâncias, a relação objetiva } \\
& \text { e o contexto do discurso, a colo- } \\
& \text { cação da frase e a entonação de } \\
& \text { uma palavra. (p. } 375 \text { ) }
\end{aligned}
$$

Ocorre que os signos linguísticos não têm um sentido unívoco quando utilizados na construção de enunciados - não há um único sentido e uma única interpretação possível para cada palavra ou conjunto de palavras. As palavras podem ser harmonizadas com diferentes sentidos, de acordo com o que se quer comunicar (na hora em que é elaborada a lei, por exemplo), de 
acordo com aquele que interpreta o texto, de acordo com as convenções históricas e culturais (Pereira, 2006, pp. 50-54).

A expressão capacidade civil, por exemplo, tem sentido diverso quando se referem à pessoa jurídica e à pessoa física; sua grafia, porém, não muda. Além disso, seja através dos enunciados normativos da legislação, seja através dos enunciados normativos da jurisprudência, seja através dos enunciados normativos dos princípios, não há como se definir previamente - na elaboração do texto legal, na elaboração da sentença, na concepção do princípio jurídico — todas as questões e os problemas que hão de se resolver com sua utilização.

Assim como a realidade da vida não é meramente objetiva (pois, felizmente, não existem axiomas de verdade que se impõem sobre todas as coisas), também uma norma jurídica não possui um sentido único intrínseco a ela, imponível indistintamente sobre todos os casos conflituosos da sociedade.

A utilização do discurso prescritivo, característico das normas jurídicas, é por si só um aspecto condicionante do tipo de definição de sentido a que se deve proceder. Ocorre que tal definição de sentido não ocorrer de forma descompassada da realidade social regulada. A linguagem jurídica possui, pois, uma dimensão técnica específica, marcada pelo uso de expressões da linguagem ordinária com uma intenção de sentido própria do mundo jurídico; contudo, tal aspecto não deveria ser supervalorizado, sob pena de causar
— ou agravar — um encastelamento do Direito, distanciando o mundo jurídico do mundo real.

Juridicamente, entretanto, há um constante caminhar no sentido da compreensão e da definição de sentido das formas especificamente jurídicas de comunicação humana. Caminhar este que objetiva tanto quanto possível uma definição de sentido jurídico dos enunciados, focando nas situações da vida que haverão de ser atingidas pelo conteúdo de tais formas comunicantes (legislação, jurisprudência, princípios).

Esse processo de definição de sentido logicamente precede as decisões jurídicas. E, para que ele ocorra da forma mais coerente e universalizável possível, recorre-se a parâmetros sistematizados que auxiliam a realização de tal operação intelectual.

\subsection{A hermenêutica e a atividade judicial}

A definição de sentido dos textos jurídicos, sobretudo os normativos, ocorre através de um processo de interpretação de cunho hermenêutico. Sua aplicação se dá, por vezes, de modo geral e prévio, com objetivo de generalidade - uma súmula de um tribunal ou os textos doutrinários, por exemplo. Ordinariamente, no entanto, os processos interpretativos são aplicados em situações jurídicas específicas, caso a caso, sobretudo no desenvolvimento processual das ações judiciais.

Entendida primariamente uma norma como um mandamento de dever ser, o seu 
sentido específico — seja ela norma constitucional, seja infraconstitucional — só pode ter uma definição na sua efetiva aplicação (ou exclusão de aplicação), numa situação da vida, a uma relação sociojurídica regulada — direta ou indiretamente — em abstrato pela própria norma. O que vem a permitir tal definição de sentido, como momento prévio do aplicar, é a interpretação jurídica. Com isso, afirma-se que a interpretação de uma norma — ou de um conjunto normativo específico é um momento prévio necessário para a sua aplicação.

Não se quer, com isso, dar a entender que uma norma jurídica seja vazia de sentido até que haja uma manifestação interpretativa concretizadora. Desde sua elaboração, estará presente no texto normativo um conjunto de signos de linguagem que imprimem uma significação mínima apreensível normalmente por todos que a interpretarem - aqui a referência se faz à mais ampla noção interpretativa, qual seja, a interpretação coloquial, feita por cada possível destinatário da norma.

Ocorre que há uma esfera de interpretação - qualificada e jurídica - que intermedia a aplicação institucional da norma. O locus competente para tal é o institucional/estatal, através das autoridades administrativas (no mais amplo significado do termo: órgãos governamentais, autoridades policiais etc.) e, principalmente, através das autoridades judiciais. Especialmente neste último nível - o judicial —, a determinação de sentido específico da norma pode correlacionar-se com os fenômenos concretos cobertos pelo âmbito possível de aplicação. Ou seja, seria tarefa específica da atividade jurisdicional o exercício de adequação normativa à realidade social subjacente, sempre respeitando os parâmetros predispostos pela teoria do Direito. Não se deve menosprezar aqui o problema que representam as idiossincrasias possíveis — mas indesejáveis — na hermenêutica judicial (Streck, 2014b, passim).

Tem-se, então, que a atividade interpretativa, para o Direito, é uma atividade de definição de conteúdo, uma atividade que possibilita concretizar a abstração das normas em face das circunstâncias de aplicação e em face das conexões axiológicas da regulação jurídica. Este é um aspecto operacionalmente relevante: as normas estão encadeadas no plano formal e material, pois a vigência e a validade de cada uma condicionam a vigência e a validade das demais. Além disso, toda norma traduz, em alguma medida, uma opção valorativa de quem a formula - e será interpretada em igual medida através de opções valorativas de quem a interpreta.

Nesse ponto, pode-se dizer que, no Direito, interpretar é, assim, definir o conteúdo de uma norma jurídica (legislada ou não) visando sua efetiva aplicabilidade a realidades concretas. Ainda, é atividade com conexão axiológica e teleológica com todo o conjunto normativo, e é conexão de adequação e razoabilidade com a realidade social abrangida pela previsão normativa. Como afirma Bonavides (1993) sobre a interpretação, ela "mostra o Direito vivendo plenamente a fase concre- 
ta integrativa, objetivando-se na realidade" (p. 357).

A hermenêutica traduz a mutabilidade histórica e a abertura semântica dos conteúdos jurídicos. Vincula-se à realidade social, pois:

\begin{abstract}
[...] a condicionalidade histórica do ordenamento jurídico revelalhe uma de suas características básicas: a dinamicidade. Característica esta que não se limita à questão da criação-revogação de normas jurídicas; abrange fundamentalmente o problema da mutação das significações normativas, o que se manifesta através dos atos de interpretação e aplicação jurídicas. (Neves, 1988, p. 20)
\end{abstract}

Portanto, a linguagem representa a matéria bruta sobre a qual a hermenêutica atua, de forma que os atos interpretantes sejam construídos argumentativamente, caso a caso.

\subsection{Linguagem e argumentação}

No âmbito do Direito, seja no plano normativo (discursos prescritivos), seja no jurisprudencial (discurso analítico-prescritivo), seja no da teoria do Direito (discurso analítico), não basta transmitir as informações, não basta o entendimento pessoal ou coletivo de quem formula o discurso jurídico - embora este seja, de qualquer forma, indispensável. Mais do que isso, é necessário tentar se propiciar uma efetiva compreensão daqueles a que o discurso de destina. Nessa linha, ensina
Morin (2011) que "compreender significa intelectualmente aprender em conjunto, comprehendere, abraçar junto (o texto e seu contexto, as partes e o todo, o múltiplo e o uno). A compreensão intelectual passa pela inteligibilidade e pela explicação." (pp. 94-95). Já a compreensão humana

$$
\begin{aligned}
& \text { [...] comporta um conhecimento } \\
& \text { de sujeito a sujeito. [...] O outro } \\
& \text { não apenas é percebido obje- } \\
& \text { tivamente, é percebido como } \\
& \text { outro sujeito com o qual nos } \\
& \text { identificamos e que identificamos } \\
& \text { conosco, o ego alter que se torna } \\
& \text { alter ego. Compreender inclui, } \\
& \text { necessariamente, um processo } \\
& \text { de empatia, de identificação e de } \\
& \text { projeção. Sempre intersubjetiva, } \\
& \text { a compreensão pede abertura, } \\
& \text { simpatia generosidade. (Morin, } \\
& \text { 2011, pp. 94-95) }
\end{aligned}
$$

Ao se formular os discursos jurídicos, portanto, é necessário se preocupar com a interação que pode ser gerada com aqueles a que se destina o discurso, e isso não apenas no plano da satisfação, mas também no plano da compreensão e da reflexão.

Obviamente, isso sempre dependerá do tipo de comunicação que se pretende obter, do meio utilizado para tanto e, claro, dos objetivos que se pretende atingir. Deve-se ter claro, entretanto, que a prescrição e a argumentação construídas têm um potencial singular a ser aproveitado. Através delas são potencializadas ou limitadas as possibilidades de comunicação efetiva entre o legislador e a população em geral, entre os profissionais jurídicos 
e a população, entre o Direito enquanto instância político-normativa e a sociedade como um todo.

Pode-se dizer que uma boa argumentação num discurso jurídico busca, de algum modo, causar ou ampliar a adesão das pessoas às teses que a elas se apresentam. Por consequência, quanto mais se conseguir transmitir o conhecimento e aumentar a intensidade dessa adesão das pessoas, possibilitando que se desencadeie nos receptores a ação pretendida (ação positiva ou abstenção) ou, ao menos, possibilitando que se crie neles uma disposição para a ação — que se manifestará no momento oportuno mais eficaz se tornará a argumentação realizada (Perelman E Olbrechts-Tyteca, 2014, p. 50). Isso naturalmente envolve que as pessoas acreditem no que está sendo comunicado (informações), pactuem com isso (opiniões) ou obedeçam a mandamentos (prescrições normativas).

O discurso jurídico, portanto, pode ser prescritivo (normativo) ou argumentativo. Evidentemente, no plano normativo, busca-se a persuasão tanto quanto no plano argumentativo. O legislador pretende, primeiramente, que as pessoas se convençam da conveniência e do mérito de se obedecer ao conteúdo prescritivo da norma. Da mesma forma, na argumentação, ainda quando aparentemente o texto seja descritivo, busca-se convencer as pessoas da correção e/ou adequação dos argumentos.

Nesse sentido, ensina Ingedore Koch (2011) que [a] interação social por intermédio da língua caracteriza-se, fundamentalmente, pela argumentatividade. Como ser dotado de razão e vontade, o homem, constantemente, avalia, julga, critica, isto é, forma juízos de valor. Por outro lado, por meio do discurso - ação verbal dotada de intencionalidade - tenta influir sobre o comportamento do outro ou fazer com que compartilhe determinadas de suas opiniões. (p. 17)

A construção do discurso jurídico, como texto articulado, deve sempre considerar a intenção de fazer o ouvinte entender sua mensagem, persuadindo, seduzindo, convencendo. Incluam-se, nesse plano do entendimento (persuasivo, sedutor ou convincente), os mecanismos argumentativos expressos, situados no nível fundamental de uso das frases, em suas significações, e os mecanismos argumentativos implícitos (não propriamente linguísticos), as manobras discursivas que dão a entender (insinuam) ou subentendem significações (Koch, 2011, pp. 150-151). Nessa perspectiva, os recursos argumentativos são vários e possibilitam a utilização de diversos mecanismos a serem priorizados de acordo com as condições do texto. Assim, pode se recorrer primariamente à ironia, à alusão, a graus de destinação do discurso, à pressuposição. Especial importância possuem, entretanto, a seleção lexical e a argumentação por autoridade.

A seleção lexical diz respeito à escolha e combinação das expressões verbais (léxico é o conjunto de palavras de uma língua). Através dela são construídas amarrações discursivas e figuras de linguagem. 
Com a seleção lexical, são estabelecidas oposições, jogos de palavras, metáforas, hipérboles etc. Já a argumentação por autoridade consiste em fazer sua própria afirmação retomando a afirmação de ou tra pessoa como reforço. O argumento por autoridade pode também ser chamado de argumento por prestígio.

O reforço do próprio argumento que utiliza o argumento de outro pode se dar tanto positiva quanto negativamente tanto na concordância de argumentos quanto na discordância e na crítica deles. É de se frisar, ainda, que a argumentação por autoridade pode se dar de forma indireta, quando se recorre a provérbios, ditos populares, expressões consagradas pelo uso.

Seja como for, a construção dos discursos jurídicos, através da linguagem, não tem como transmitir mensagens exatas e inequívocas, pois, por serem realizadas através da linguagem, sempre estarão sujeitas à diversidade de interpretação e, em decorrência, ao recurso à argumentação. Novamente aqui fica ressaltada a importância da atividade hermenêutica, com critérios e métodos que possibilitem a mais adequada interpretação possível.

A análise da atividade de interpretação jurídica mostra, por si só, que o Direito, enquanto previsão de situações, é incompleto, é carente, limitado em abrangência e finito temporalmente (Canaris, 1995, passim). Mostra que as incompletudes do sistema jurídico precisam ser supridas para que ele cotidianamente tenha eficácia jurídica e, sobretudo, efetividade social.
Para proceder ao suprimento das incompletudes e limitações do Direito, o hermeneuta há de realizar a adequação das previsões abstratas legais às situações concretas do mundo da vida que sejam postas sob seu poder de decisão. Não faz isso, porém, sem base anterior: a doutrina e a jurisprudência constroem uma gama de interpretações prévias de sentido para os enunciados normativos e o sistema jurídico, e os juízes evidentemente se valem disso.

Mesmo assim, tal adequação se mostrará, muitas vezes, deficiente e/ou insuficiente. Por um singelo motivo: a realidade concreta do mundo da vida é dinâmica, movimenta-se, redimensiona-se constantemente. Enquanto isso, as previsões legais, por mais que possam ser alteradas e revisadas com frequência, são originalmente estáticas. O "mundo da vida" no plano do cotidiano real não se conforma ao "mundo do Direito" - plano do ser versus plano do dever ser. No entanto, deve-se ter como meta minimizar as distâncias entre os dois.

Para tanto, o intérprete jurídico precisa galgar horizontes interpretativos novos, há de avançar em relação ao texto legal, numa direção que, por um lado, inove a norma legal abstrata em seu sentido estrito (conectando-a com os valores superiores constitucionais) e, por outro, supere a moldura legal do Direito para conectá-lo efetivamente à realidade social. O uso dos métodos interpretativos deve ser visto, assim, como meio para um fim: alcançar a definição de sentido hábil a justificar a aplicação do Direito. 
As zonas de separação entre interpretação jurídica e criação de novos conteúdos são bastante vagas no Direito. A interpretação será sempre um processo intelectual de concretização de sentidos normativos, em face de argumentações preexistentes. Nessa concretização, será definido o sentido adequado de uma norma ou um conjunto de normas jurídicas, pensadas em relação à sua possibilidade de aplicação a um determinado fato. E tal definição de sentido acaba tendo algum grau de criação de novos conteúdos, pois o próprio processo hermenêutico é argumentativo.

Ocorre que tal possibilidade real de criação de novos conteúdos no processo hermenêutico de concretização do Direito não pode ser ilimitada. O ponto de equilíbrio e referência para tanto está no papel singular que a Constituição - e, por óbvio, a interpretação constitucional - pode exercer em termos sistemático-valorativos.

\section{A INTERPRETACÃO SISTEMÁTICA CONSTITUCIONAL}

Os conteúdos do Direito aplicáveis para a solução dos problemas da vida real não nascem do nada: há um nível normativo mínimo que açambarca todos os setores da vida social. Entretanto, para além desse mínimo, as situações da vida pedem concretizações hermenêuticas que, em alguma medida, são inovadoras. Ocorre que as inovações de conteúdo não podem decorrer de subjetivismos do intérprete que desvirtuem os parâmetros normativos mínimos do sistema jurídico (Streck, 2014a). Aqui sobressai a importância da Constituição enquanto sistema normativo axioteleológico.

\subsection{0 paradigma sistemático para a hermenêutica}

Interpretações semânticas são necessárias juridicamente, mas insuficientes, pois têm limitada abrangência. Interpretações teleológicas são necessárias, mas igualmente insuficientes, pois as finalidades somente ganham corpo através da conformidade com outras finalidades e valores. Interpretações devem sempre ser, explícita ou implicitamente, sistemáticas, para que se permita o encadeamento dos diversos mecanismos hermenêuticos, ora enfatizando um, ora enfatizando outro.

A interpretação sistemática possibilita encarar a norma aplicada como parte de um contexto maior - possibilita encarar a norma como um fenômeno complexo, uma parte de um todo. Por decorrência, a leitura da norma constitucional deveria sempre ser feita com atenção ao conjunto normativo da Constituição, com o todo da Constituição.

Isso impulsionaria o hermeneuta no sentido da adoção de um critério axiológico principiológico, que consagre o papel hierárquico das normas constitucionais. Conduz, pois, à imprescindibilidade da interpretação sistemática do texto normativo constitucional, calcada em valores e intencionalidades finalísticas. Afinal,

[...] toda a interpretação de uma norma tem de tomar em consideração, como vimos, a cadeia de 
significado, o contexto e a sede sistemática da norma, a sua função no contexto da regulação em causa. [...] o ordenamento jurídico no seu conjunto, ou pelo menos grande parte dele, está subordinado a determinadas ideias jurídicas diretivas, princípios ou pautas gerais de valoração, a alguns dos quais cabe hoje o escalão de Direito Constitucional. [...] A descoberta das conexões de sentido em que as normas e regulações particulares se encontram entre si e com os princípios diretivos do ordenamento jurídico, e a sua exposição de um modo ordenado, que possibilite a visão de conjunto - quer dizer, na forma de um sistema - é uma das tarefas mais importantes da Jurisprudência científica. (Larenz, 1989, pp. 531-532)

É em tal esteira que Canaris se refere à capacidade de derivação teleológica ou valorativa do sistema, em que, através de procedimentos interpretativos sistemáticos, se desdobra a norma constitucional em diversos sentidos específicos, possibilitando que os valores superiores nela consagrados sejam aplicáveis em todas as esferas possíveis de sua regulação jurídica (Canaris, 1989, passim). Isso permite a junção da força normativa hierárquica com a derivação hermenêutica concretizadora e reforça o papel condicionante da Constituição em relação a todo o sistema jurídico.

O termo derivação dirige-se para as possibilidades de ordenação de sentido que a interpretação sistemática de caráter axioteleológico possibilita, e não para uma mera dedução formalista. Não há imperativos hierárquicos de sentido que imponham uma direção absoluta e exclusiva para o intérprete. Existem, sim, imperativos dialéticos - embora normativos — que indicam os caminhos justificados pela principiologia constitucional do sistema jurídico.

Tem-se, assim, uma perspectiva que: (a) por um lado, parte dos valores consagrados normativa e constitucionalmente no sistema; (b) por outro lado, parte das intenções e objetivos reconhecidos (finalidades normativas) para se apontar novas valorações derivadas, seja em termos generalizadores, seja em termos concretizadores. Em outras palavras, seria feita a leitura valorativa normativa da Constituição, agregada de uma busca de racionalização valorativa calcada sobre as finalidades constitucionais (também normatizadas), buscando adequar as diversas áreas do Direito às matrizes constitucionais, resultando que, "em seus pontos fundamentais, se toca, por assim dizer, a interpretação conforme a Constituição com a interpretação sistemática, vez que ambos os métodos têm em vista a manutenção da ausência de contradição no interior do sistema" (Freitas, 1995, p. 530).

A interpretação jurídica se efetiva pelo esclarecimento/definição/escolha do significado adequado das enunciações e das proposições jurídicas normativas, para que se tornem aplicáveis a outras proposições ou aplicáveis diretamente aos casos concretos, e para que possam se constituir como determinantes jurídicas (novamente, ressalva-se que existem 
condicionantes não jurídicas) de soluções de problemas. A interpretação será tão sistematicamente satisfatória quanto as proposições dela decorrentes puderem ser incluídas como conformadas "no todo pré-existente da ordem jurídica" (Canaris, 1989, p. 173). O sistema, assim, funciona como referência localizante da ligação de sentido da ordem jurídica, de modo que se possa apurar a sua aceitabilidade formal e material, ponderando a prevalência de valores no intuito de evitar contradição insolúvel entre eles.

Na obtenção do Direito aplicável, a interpretação constitucional sistemática apresenta para o sistema jurídico dois papéis especialmente significativos no âmbito hermenêutico: um papel negativo, consistente na prevenção de contradições absolutas de valores - superação de antinomias - , e um papel positivo, con sistente na determinação e na integração das lacunas.

A determinação e integração de lacunas trazem à luz um aspecto primordial do sistema: a sua função positiva de "desenvolver o Direito de acordo com o peso interior dos seus princípios constitutivos ou 'gerais'" (Canaris, 1995, p. 178).

Significa, basicamente, que há uma so bredeterminação de sentido que implica a retirada de uma solução jurídica para um caso não regulado a partir de um princípio geral. O que gera um processo de movimentação de conteúdo, pois, se o princípio geral "injeta" uma direção valorativa na apreciação do caso lacunar, a partir das previsões singulares, poderão ser elaborados novos conteúdos jurídicos ou dar partida a novos intuitos valorativos.

O sistema jurídico, reafirma-se, não é completo, finito, imutável, nem infenso a limitações. Pelo contrário: as limitações lhe são naturais. O sistema é, mesmo sob o propugnado prisma axioteleológico, um ponto de referência, destinado a dar um sentido direcionador e um ponto de ligação geral para o objeto Direito.

Mas seria ilusório imaginar que, com isso, se pudesse dar respostas imediatas a todas as necessidades práticas do universo jurídico social, pois estas se renovam constantemente, devendo o Direito adequar-se a elas. A ideia de sistema jurídico, mesmo quando concebida nesse prisma axiológico e teleológico, tem, pois, seus limites, embora sejam eles mais operacionais do que necessariamente estruturais.

\subsection{A interpretaç̃o constitucional sistemática}

A partir da metade do século XX, consagrou-se definitivamente a ideia de que a Constituição, no âmbito do estado de Direito, é o referencial básico no ordenamento jurídico de um país, já que nela está a base política e jurídica da estruturação dos poderes democráticos.

O texto normativo constitucional compreende uma diversa gama de normas. Existem normas transitórias, destinadas a regular situações de acordo com (ou até) o advento de certas circunstâncias; outras podem ser postas como normas constitucionais ordinárias (num sentido lato); por fim, pode-se falar em normas-princípios. 
Estas resguardam normativamente os valores centrais da regulação social, formando princípios axiológicos referenciais.

A Constituição configura, assim, um sistema normativo articulado em torno de princípios - sistema axiológico e teleo lógico. Sua base é normativa (centrada em mandamentos de dever ser) e serve como fonte dos princípios do sistema jurídico, consagrando seus valores superiores e finalidades a serem atingidas na operacionalização do Direito.

No reconhecimento do estatuto especial concedido pelo legislador constituinte a determinados valores básicos, reside a prevalência principiológica da Constituição. Essa prevalência vincula axiologicamente (valorativamente) o próprio conjunto normativo constitucional, formando conexões de sentido. E a operacionalização vinculatória de adequação valorativa, que busca atingir finalidades, forma uma globalidade potencialmente ordenada e unitária: o sistema constitucional.

Canotilho e Moreira (1991) posicionam-se em sentido semelhante, quando afirmam que

[...] ao considerar-se essencial na interpretação da Constituição as conexões de sentido, pretende-se sobretudo pôr em relevo que um preceito constitucional não deve ser considerado isoladamente e interpretado apenas a partir dele próprio. É que, formando a Constituição uma unidade de sentido, deve tomar-se em conta o seu conteúdo global, o que per- mite, designadamente, conferir o devido relevo, em sede interpretativa, aos princípios jurídicos e políticos fundamentais da Constituição. (p. 53)

Ora, se privilégio valorativo foi dado a ideais que formam princípios temáticos prevalentes para o Direito em sentido axiológico, e ímpares normativamente, o intérprete há de vislumbrar a ordenação e proceder a uma adequação valorativa dos casos concretos aos valores e às finalidades do texto constitucional. Com isso, deve também ter presente a unidade de sentido a ser perseguida, concatenando as normas em geral às normas-princípios - diretrizes de conteúdo do sistema jurídico. Por exemplo, não basta se afirmar que prevalece na Constituição o princípio da dignidade da pessoa humana. É necessário que sejam interpretados os diversos dispositivos constitucionais, sobretudo para a discussão e a solução de casos reais, vinculados entre si e em conformidade com tal princípio (Alexy, 1993, passim).

O caráter axiológico e sistemático da Constituição se impõe, assim, precisamente como ponto de partida da interpretação constitucional. A Lei Maior traz normas com características especiais para o sistema jurídico como um todo. E o faz — reafirma-se - exatamente por consagrar e exaltar os valores basilares definidores de conteúdo da ordem do Direito e do Estado.

Como bem acentua Enterria (1982), é essencial 
[...] o valor específico da Constituição não como uma norma qualquer, de qualquer conteúdo, mas sim precisamente como portadora de alguns determinados valores materiais. Estes valores não são simples retórica, não são [...] simples princípios "programáticos", sem valor normativo de aplicação possível; pelo contrário, são justamente a base plena do ordenamento, a que há de dar a este seu sentido próprio, a que há de presidir, portanto, toda sua interpretação e aplicação. (p. 98)

A interpretação constitucional, assim, há de ser prioritariamente interpretação sistemática. Com força nas normas-princípios e salientes os elementos de ordenação e unidade. A interpretação sistemática relaciona-se com a busca da melhor significação sistemática, aos princípios, às normas e aos valores jurídicos, numa hierarquia teleológico valorativa destinada à solução de casos concretos (Freitas, 1995, passim).

A ação do intérprete constitucional deve se pautar num primeiro plano, portanto, na adequação valorativa, para então buscar a ordenação de sentido, a racionalização ordenadora, o que se faz organizando o pensamento sistemático em função das finalidades a serem atingidas.

\subsection{Unidade sistemática}

Voltando-se à afirmação inicial, o Direito existe numa constante crise dialética, em que os conceitos passados morrem aos poucos sem que sejam de pronto substituídos por conceitos novos. Em vez de substituição, o que se tem é uma construção hermenêutica fragmentária, marcada por influências ideológicas e valorativas daqueles que interpretam os conteúdos, de forma a (re)defini-los.

Em função disso, deve-se preservar a unidade de conteúdos da Constituição através da interpretação sistemática. Sobressai aqui a importância da constante atenção às normas constitucionais consagradoras de direitos fundamentais, enquanto diretrizes de conteúdo para qualquer sistematicidade constitucional (Coelho, 2003; Barcellos, 2002).

O texto constitucional como um todo deve ser entendido nas múltiplas vinculações com os seus princípios gerais, cuja denominação constitucional específica é variável: fundamentos, objetivos, direitos fundamentais, princípios.

Na Constituição, cada tema normativo específico tem submissão valorativa aos princípios temáticos (formando um subsistema constitucional). Tome-se como exemplo, na Constituição brasileira de 1988, o princípio da igualdade entre homem e mulher como centro da organização familiar, sediado no artigo 226, que deve ser compreendido em consonância com o inciso I do artigo $5^{\circ}$ da mesma Constituição Federal, mas que, ao mesmo tempo, serve de diretriz valorativa para todo o ordenamento civil das relações familiares.

Unidade principiológica (valorativa) e ordenação teleológica (finalística) deveriam, pois, ser os guias hermenêuticos essen- 
ciais, de forma a resguardar o caráter sistêmico da Constituição. Afinal, como afirma Bonavides (1993),

\section{[...] a Constituição é basicamente unidade, unidade que repousa so- bre princípios: os princípios consti- tucionais. Esses não só exprimem determinados valores essenciais — valores políticos ou ideológicos - senão que informam e perpas- sam toda a ordem constitucional, imprimindo assim ao sistema sua feição particular, identificável, in- confundível, sem a qual a Consti- tuição seria um corpo sem vida, de reconhecimento duvidoso, se não impossível. (p. 110)}

Ora, a linha configurante da aplicação constitucional — do que a interpretação é o passo mais importante, mais decisivo - passa pela submissão de conteúdo e sentido da abordagem normativa (geral e temática) a uns poucos princípios referenciais, sustentáculos das valorações preponderantes para cada situação jurídica problemática nas sociedades organizadas constitucionalmente (Viehweg, 1986, passim).

A referência às valorações imponíveis em cada caso problemático nos remete à tópica. Definida como técnica hermenêutica do pensamento problemático, ela é baseada nos tópicos - que seriam pontos de vista de grande utilização e aceitos em geral, constitutivos de premissas aplicáveis aos problemas jurídico-sociais concretos.

Isso ganha especial significação no campo do sistema constitucional, em que os dispositivos normativos são mais abertos, já que não se destinam à regulação direta de condutas e procedimentos. Há de se entender, porém, que as valorações principiológicas de problemas a partir da Constituição guardam algumas nuances tópicas, sem que, no entanto, prescindam da sua remissão ao sistema, à ordenação valorativa global. Com o que fica patente que a tópica e o sistema - este enquanto axioteleológico - não se excluem, mas sim se complementam (Canaris, 1995, pp. 243-277).

Como exemplo, é inviável discutir-se coerentemente a função social dos contratos, erigida a princípio explícito pelo Código Civil brasileiro (em seus artigos 187 e 421), sem contextualizá-la com as diretrizes constitucionais para as relações entre particulares, e entre estes e a Administração Pública. A ação do intérprete ganha corpo, vê-se na conjugação da ordenação de sentido com a unidade principiológica, conjunção esta direcionadora do sentido jurídico-valorativo a prevalecer. Ação interpretante que, assim, se faz necessariamente sistemática.

\section{CONCLUSÕES}

A interpretação constitucional sistemática, assim, há de se pautar pela hierarquização normativo-valorativa. O interpretante deve operar com o conteúdo normativo constitucional, material constituído por normas formal e materialmente reconhecidas como especiais para a organização social. Seu ponto de referência há de ser, pois, o conjunto normativo constitucional. Isso reduziria 
a pessoalidade ideológica (solipsismo) do intérprete em benefício da unidade axiológica do sistema.

A operação interpretativa constitucional, porém, deve respeitar às características específicas e intrínsecas desta - já que ela é supremamente um complexo de valores, sediados em princípios, com estrutura e imperatividade normativas. Para o intérprete atingir essa dimensão dos valores constitucionais, procede-se à adequação valorativa, nos moldes de Canaris (1995), pensando os valores jusfundamentais reconhecidos constitucionalmente em todas as suas consequências, mas buscando solucionar suas eventuais contradições correlatas e possíveis contradições com novos valores ascendentes.

Com isso, seria atendido ao pressuposto de ordenação do sistema, antes abordado. Mais precisamente, nos termos de Canaris, seria atingido o pressuposto de uma ordem teleológica constitucional.

A fim de atender aos reclames principiológicos, o intérprete deve buscar a concretização das normas constitucionais jusfundamentais, formando vinculações efetivas - de aplicação em concreto entre regras em geral e princípios constitucionais. Isso se justifica em torno da necessidade de as regras em geral serem acordes com os princípios gerais e específicos da Constituição, facilitando uma concretização valorativa.

A partir da abordagem que parte da análise do conjunto para a singularização dos princípios (partindo-se das disposições gerais constitucionais para a solução de problemas através ou com a aplicação de princípios), reafirmam-se ou formam-se novos pressupostos valorativos. Assim, na concretização das normas, por meio de sua interpretação e aplicação, a dinâmica dialética principiológica vai movimentando e remodelando as cadeias valorativas do Direito. Isso possibilita evitar, no plano da fundamentação teórica, a assunção de contradições efetivas insanáveis.

Com isso, estaria se satisfazendo o pressuposto de unidade valorativa do sistema, ou, nos termos de Canaris, "unidade axiológica" constitucional. De um modo aberto, dinâmico e atento às mutabilidades jurídico-sociais, a tarefa do intérprete, então, estaria justificada na perspectiva de hierarquização axiológica e principiológica, sobrepondo as normas constitucionais jusfundamentais (portadoras dos valores superiores do sistema jurídico) a todas as áreas do Direito.

O conjunto reflexivo aqui exposto culmina, assim, num imperativo interpretativo teleológico de duas faces: (a) por um lado, a busca constante da superação (sem negar sua existência) das eventuais contradições de sentido jurídico, suas antinomias existentes no sistema jurídico como um todo; (b) a busca hermenêutica de diretrizes valorativas sistemáticas para solucionar os casos concretos em geral, a partir do conteúdo e da direção de sentido prevalentes constitucionalmente sob a ótica de um sistema constitucional axioteleológico. 


\section{REFERÊNCIAS BIBLIOGRÁFICAS}

Alberti, V. (1996). A existência na história: revelações e riscos da hermenêutica. Revista Estudos Históricos, 9(17), 31-58. Recuperado de http:// bibliotecadigital.fgv.br/ojs/index.php/reh/ issue/view/283.

Alexy, R. (1993). Teoría de los derechos fundamentales. Madri: Centro de Estudios Constitucionales.

Aranguren, J. L. (1975). Comunicação humana: uma sociologia da informação. Rio de Janeiro: Jorge Zahar; São Paulo: Edusp [Editora da Universidade de São Paulo].

Barcellos, A. P. de. (2002). A eficácia jurídica dos princípios constitucionais: o princípio da dignidade da pessoa humana. Rio de Janeiro: Renovar.

Bonavides, P. (1993). Curso de direito constitucional (4 ed.). São Paulo: Malheiros.

Canaris, C. W. (1995). Pensamento sistemático e conceito de sistema na ciência do Direito. Lisboa: Calouste Gulbenkian.

Canotilho, J. J. G., \& Moreira, V. (1991). Fundamentos da constituição. Coimbra: Coimbra Editora.

Coelho, E. M. (2003). Direitos humanos, globalização de mercados e o garantismo como referência jurídica necessária. São Paulo: Juarez de Oliveira.

Enterria, E. G. de. (1982). La constitución como norma y el tribunal constitucional (2 ed.). Madri: Civitas.

França, R. L. (1994). Hermenêutica jurídica (3 ed.). São Paulo: Saraiva, 1994.

Freitas, J. (1995). Interpretação sistemática do direito. São Paulo: Revista dos Tribunais.
Gadamer, H. G. (2003). Verdade e método I: traços fundamentais de uma hermenêutica filosófica (5 ed.). Petrópolis: Vozes.

Koch, I. G. V. (2011). Argumentação e linguagem (13 ed.). São Paulo: Cortez.

Larenz, K. (1989). Metodologia da ciência do direito (2 ed.). Trad. José Lamego. Lisboa: Calouste Gulbenkian.

Morin, E. (2011). Os sete saberes necessários à educação do futuro ( 2 ed.). São Paulo: Cortez.

Neves, M. (1988). Teoria da inconstitucionalidade das leis. São Paulo: Saraiva.

Peixinho, M. M. (2003). A interpretação da constituição e os princípios fundamentais: elementos para uma hermenêtica constitucional renovada (3 ed.). Rio de Janeiro: Lúmen Júris.

Pereira, R. V. (2006). Hermenêutica filosófica e constitucional. Belo Horizonte: Del Rey.

Perelman, C., \& Olbrechts-Tyteca, L. (2014). Tratado da argumentação: a nova retórica (3 ed.). São Paulo: Martins Fontes.

Streck, L. L. (2014a). Hermenêutica jurídica e(m) crise. Uma exploração hermenêutica da construção do Direito (11 ed.). Porto Alegre: Livraria do Advogado.

Streck, L. L. (2014b). Jurisdição constitucional e decisão jurídica (4 ed.). São Paulo: Editora Revista dos Tribunais.

Vanoye, F. (1986). Usos da linguagem: problemas e técnicas na produção oral e escrita (7 ed.). São Paulo: Martins Fontes.

Viehweg, T. (1986). Tópica y jurisprudencia. Madri: Taurus. 